\title{
THE PARACHUTE-LIKE ASYMMETRIC MITRAL VALVE AND ITS TWO PAPILLARY MUSCLES
}

Petra W. Oosthoek, $\mathrm{PhD}^{\mathrm{a}}$ Arnold C. G. Wenink, MD, $\mathrm{PhD}^{\mathrm{a}}$

António J. Macedo, $\mathrm{MD}^{\mathrm{b}}$

Adriana C. Gittenberger-de Groot, $\mathrm{PhD}^{\mathrm{a}}$

\begin{abstract}
Objectives: The morphologic features of parachute-like asymmetric mitral valves are described to discriminate this anomaly from parachute mitral valves. Background: Mitral valves with unifocal attachment of chords have been called "parachute valves," independent of the number of papillary muscles. Therefore the anomaly involving two papillary muscles has not received separate attention. Methods: The gross anatomy of 29 mitral valves with focalized attachment of chords was studied. Results: In 28 of the autopsy specimens asymmetric mitral valves with two papillary muscles were present, and one of the muscles was elongated, located higher in the left ventricle with its tip reaching to the anulus, and attached at both its base and lateral side to the left ventricular wall. The valve leaflets could be directly attached to this abnormal muscle that received few chords or, in three hearts, no chords at all, resulting in an oblique and eccentric orifice. Because of the focalized attachment of chords to one of the two papillary muscles, we call this malformation "parachute-like asymmetric mitral valve." We found only one "true parachute mitral valve," that is, one having a single papillary muscle that received all chords. Conclusions: The morphologic features of asymmetric mitral valves are essentially different from those of true parachute valves. A distinction between these two anomalies will contribute to recognition by the pediatric cardiologist and surgeon. (J Thorac Cardiovasc Surg 1997;114:9-15)
\end{abstract}

$T_{\mathrm{m}}^{\mathrm{h}}$ he parachute mitral valve is a congenital cardiac malformation that causes stenosis of the mitral valve and is often found in combination with other obstructive anomalies of the left side of the heart. ${ }^{1}$ Parachute mitral valves were originally defined as having all chords converging to insert into one major papillary muscle. Valves with two papillary muscles that were immediately adjacent, thus yielding the effect of a single papillary muscle, were included in the parachute group. ${ }^{1,2}$ However, in a later study "parachute mitral valves" and "mitral valves with one single papillary muscle" were discriminated

From the Department of Anatomy, Leiden University, Leiden, The Netherlands, ${ }^{a}$ and the Serviço de Cardiologia Pediátrica, Hospital de Santa Marta, Lisboa, Portugal. ${ }^{b}$

Supported by The Netherlands Heart Foundation, grant 93.057, and by a Collaborative Research Grant from the Association of European Pediatric Cardiologists.

Received for publication August 8, 1996; revisions requested Dec. 5, 1996; revisions received Dec. 30, 1996; accepted for publication Dec. 31, 1996.

Address for reprints: A. C. G. Wenink, MD, PhD, Department of Anatomy, P.O. Box 9602, 2300 RC Leiden, The Netherlands.

Copyright (C) 1997 by Mosby-Year Book, Inc.

$0022-5223 / 97 \$ 5.00+0 \quad \mathbf{1 2 / 1 / 8 0 0 9 9}$ from each other, ${ }^{3}$ although the differences in morphologic features between these two mitral valve anomalies were not explained, which made this use of terms rather confusing.

In 1974, Rosenquist ${ }^{2}$ described mitral valves with two papillary muscles but with all chords being inserted into one of them. Despite different morphologic features, the term parachute mitral valve was also used for this mitral valve anomaly. In a later description, the cases with two papillary muscles, of which one could be hypoplastic, were discriminated from the cases with one papillary muscle. The parachute valves with one papillary muscle were claimed to represent fusion of the two papillary muscles. ${ }^{4}$ Although this term might be rather dynamic it was not meant to explain the developmental background of this malformation, which is still largely unknown.

To set new light on this confusing area of morphology and terminology of parachute mitral valves we studied hearts in our autopsy collection with unifocal attachment of chords. We decided to discriminate the mitral valves with two papillary muscles from the true parachute valves by calling them "parachute-like asymmetric mitral valves." 
Table I. Associated pathologic conditions in hearts with parachute-like asymmetric mitral valves or parachute valve

\begin{tabular}{|c|c|c|}
\hline Group & Case & $\begin{array}{l}\text { Associated cardiac } \\
\text { pathologic condition }\end{array}$ \\
\hline \multirow{6}{*}{$\begin{array}{l}\text { Asymmetric, abnormal } \\
\text { ALPM } \\
\text { Grade I }\end{array}$} & 1 & $\mathrm{AoCo}$ \\
\hline & 2 & $\begin{array}{l}\text { Abnormal PV return, per- } \\
\text { sistent left SVC }\end{array}$ \\
\hline & 3 & $\begin{array}{l}\text { AoCo, Ao hypoplasia, } \\
\text { VSD, PDA, PFO }\end{array}$ \\
\hline & 4 & Ao hypoplasia, TGA, VSD \\
\hline & 5 & $\begin{array}{l}\text { Abnormal PV return, per- } \\
\text { sistent left SVC }\end{array}$ \\
\hline & 6 & $\begin{array}{l}\text { Ao arch hypoplasia, VSD, } \\
\text { PFO, PDA }\end{array}$ \\
\hline \multirow{17}{*}{$\begin{array}{l}\text { Asymmetric, abnormal } \\
\text { ALPM } \\
\text { Grade II }\end{array}$} & 7 & AoInt, TGA \\
\hline & 8 & $\mathrm{AoCo}$ \\
\hline & 9 & $\begin{array}{l}\text { AoCo, bicuspid aortic } \\
\text { valve }\end{array}$ \\
\hline & 10 & AoCo, VSD \\
\hline & 11 & VSD, TGA \\
\hline & 12 & VSD, DORV \\
\hline & 13 & PDA \\
\hline & 14 & $\begin{array}{l}\text { Two muscular VSDs, Ao } \\
\text { hypoplasia }\end{array}$ \\
\hline & 15 & $\begin{array}{l}\text { AoCo, Ao hypoplasia, } \\
\text { VSD }\end{array}$ \\
\hline & 16 & $\begin{array}{l}\text { Preductal Ao atresia, mus- } \\
\text { cular and membranous } \\
\text { VSD, overriding Ao }\end{array}$ \\
\hline & 17 & AoCo, VSD, Ao stenosis \\
\hline & 18 & AoCo, muscular VSD \\
\hline & 19 & $\mathrm{AoCo}$ \\
\hline & 20 & VSD \\
\hline & 21 & Ao hypoplasia, T. of Fallot \\
\hline & 22 & $\begin{array}{l}\text { Ao valve stenosis, fibro- } \\
\text { elastosis }\end{array}$ \\
\hline & 23 & $\begin{array}{l}\text { Pulmonary atresia, VSD, } \\
\text { ASD }\end{array}$ \\
\hline \multirow{3}{*}{$\begin{array}{l}\text { Asymmetric, abnormal } \\
\text { ALPM } \\
\text { Grade III }\end{array}$} & 24 & T. of Fallot \\
\hline & 25 & VSD \\
\hline & 26 & VSD, bicuspid aortic valve \\
\hline \multirow{3}{*}{$\begin{array}{l}\text { Asymmetric, abnormal } \\
\text { PMPM } \\
\text { Grade II }\end{array}$} & 27 & $\mathrm{AoCo}$ \\
\hline & 28 & $\mathrm{AoCo}$ \\
\hline & & \\
\hline Parachute valve & 29 & AoCo, VSD \\
\hline
\end{tabular}

$A L P M$, Anterolateral papillary muscle; $A o$, aorta; $A O C o$, aortic coarctation; AoInt, aortic arch interruption; $A S D$, atrial septal defect; $D O R V$, double-outlet right ventricle; $P D A$, persistent ductus arteriosus; $P F O$ persistent foramen ovale; $P M P M$, posteromedial papillary muscle; $P V$, pulmonary venous; $T$. of Fallot, tetralogy of Fallot; $T G A$, transposition of the great arteries; $S V C$, superior vena cava; $V S D$, ventricular septal defect.

\section{Material and methods}

Morphology. Abnormal mitral valves were found in 129 autopsy specimens. Twenty-nine of these hearts had focalized attachment of chords to one papillary muscle. Twenty-eight of these hearts had two papillary muscles and an asymmetric distribution of chords, that is, all chords or the majority of them were attached to one of the two muscles. We called this malformation "parachute-like asymmetric mitral valve." Only one heart had a "true parachute," that is, the arrangement in which one single papillary muscle received all chords. The mean age at death of the children from whom the hearts were obtained was 12 months and ranged from 1 day (born at 30 weeks of amenorrhea) to 15 years. In none of the hearts was the parachute or parachutelike asymmetric mitral valve an isolated cardiovascular abnormality (Table I). Hearts with an atrioventricular septal defect and a parachute-like morphology ${ }^{5}$ and hearts with a hypoplastic left ventricle were not included in this study.

Nineteen normal hearts (Fig. 1) were studied as control specimens. The ages of these children at death ranged from 1 day (born at 28 weeks of amenorrhea) through 6 years with a mean of 14 months; there were 7 boys, 9 girls, and 3 of unknown sex.

Measurements. Twenty-six hearts with a parachute-like asymmetric mitral valve and abnormal anterolateral valvular apparatus and 19 normal hearts were used for measurement of the valve and tension apparatus. The two asymmetric mitral valves with an abnormal posteromedial apparatus and the true parachute valve were not included in the quantitative analysis.

At the site of each commissure the following values were determined (Fig. 2): the length of the ( 1 on Fig. 2) leaflets and (2) chords that were nearest to the midline of the aortic leaflet; the length of the papillary muscle from (3) the base to the tip and from (4) the base to the attachment of the chords; and the distance from the apical endocardium to (5) the base or (6) the tip of the papillary muscle. The diameters of the mitral and tricuspid valve anuli (7) and the diameter of the orifice of the mitral valve at the free rim of the valve leaflets were determined with a Hegar probe. The left ventricular length (8) was measured from the aortic orifice to the apical endocardium.

Statistical analysis. The values of the 26 abnormal hearts were compared with those of the 19 normal hearts by a $t$ test for equality of means (SPSS program, version 5.0, SPSS, Inc., Chicago, Ill.). Significant differences were defined as $p<0.05$.

\section{Results}

Morphology. The 28 asymmetric mitral valves were characterized by one normal and one abnormal papillary muscle. Twenty-six of these had an abnormal anterolateral papillary muscle. Only in two cases was the posteromedial papillary muscle abnormal. We observed a spectrum of asymmetry of the mitral valve because one valvulopapillary muscle complex was slightly to severely abnormal (Fig. 3). We subdivided the 28 hearts into three groups by grade (Table I).

Grade I (Fig. 3, a through $c$ ). Six hearts had slightly asymmetric mitral valves. The anterolateral papillary muscle was elongated and the chords were 

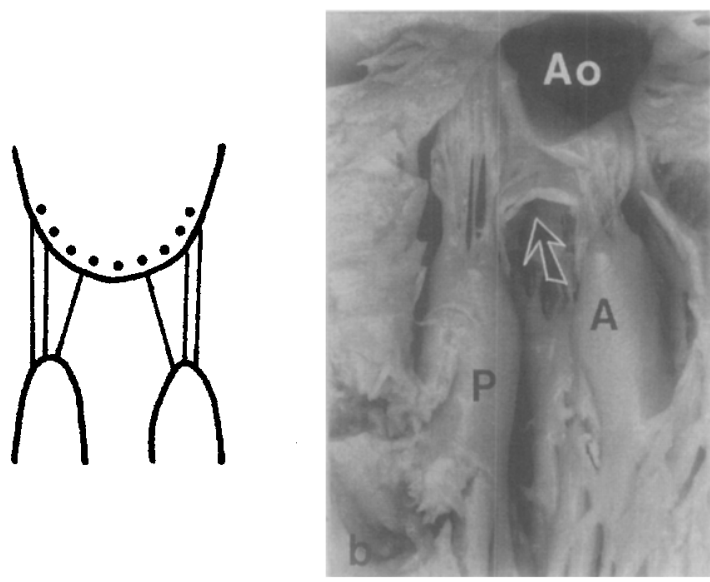

a

Fig. 1. A schematic drawing (a) and a photograph (b) of a normal mitral valve from a newborn child. The orifice is indicated by dots (a) and by a thick arrow (b). $A$, Anterolateral papillary muscle; $A o$, aorta; $P$, posteromedial papillary muscle.

attached to the lateral side of this papillary muscle. In some hearts the two valve leaflets near the anulus were directly attached to the abnormal papillary muscle.

Grade II (Fig. 3, $d$ through $f$ ). Nineteen abnormal hearts had more obvious asymmetry of the mitral valves. In two of these hearts the posteromedial papillary muscle was abnormal. The elongated papillary muscle and especially the tip was located close to the mitral valve anulus. In addition, the abnormal papillary muscle was attached at its lateral side to the left ventricular free wall. At the abnormal commissure the valve leaflets were short and directly attached to the tip of the papillary muscle and only a few short chords or almost no chords were present. This remarkable attachment of chords and leaflets caused an asymmetric location of the valve orifice, leading to an oblique position in the left ventricle. Moreover, the attachment of the leaflets and the short chords prevented opening of the orifice at the abnormal commissure (Fig. 3, $f$ ). Nine of these mitral valves had a smaller orifice diameter compared with the annular diameter.

Grade III (Fig. 3, $g$ through $i$ ). Three hearts were characterized by the absence of chords to one papillary muscle. As in grades I and II, two papillary muscles were present, one of them elongated and displaced to the base of the heart: the tip of the abnormal papillary muscle was located near the mitral valve anulus and the papillary muscle was attached at its lateral side to the left ventricular wall.



Fig. 2. Schematic drawing of a mitral valve in which the parts that were measured are indicated by arrows (numbers identified in the Material and methods section).

The valve leaflets were directly attached to the abnormal papillary muscle and their edges were partly attached to each other at this site. Therefore opening of the commissure was not possible on the abnormal side, and the orifice was oblique and had an eccentric position (Fig. $3, h$ ). All three mitral valves with complete unifocal attachment of chords had a stenotic orifice, that is, a smaller orifice diameter compared with the diameter of the anulus.

Only one heart had a true parachute mitral valve, that is, only one papillary muscle to which all chords were attached (Fig. 4). The valvulopapillary muscle complex was located somewhat posteriorly. The orifice was located between the chords, just above the papillary muscle, the valve tissue formed a funnel, and no cleft was present. Because of this centrally located valve orifice, the parachute valve was strikingly different from the asymmetric valves with their characteristic oblique orifice.

Quantitative data. The left ventricular lengths in the normal hearts and abnormal hearts did not differ significantly (Table II). The ratios of the mitral and tricuspid anuli and the ratios of the mitral valve anulus and left ventricular length were significantly smaller in the abnormal hearts (Table II). We 
a
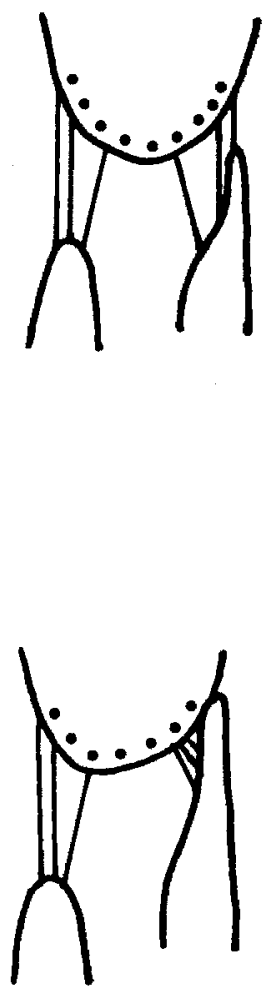

d



9
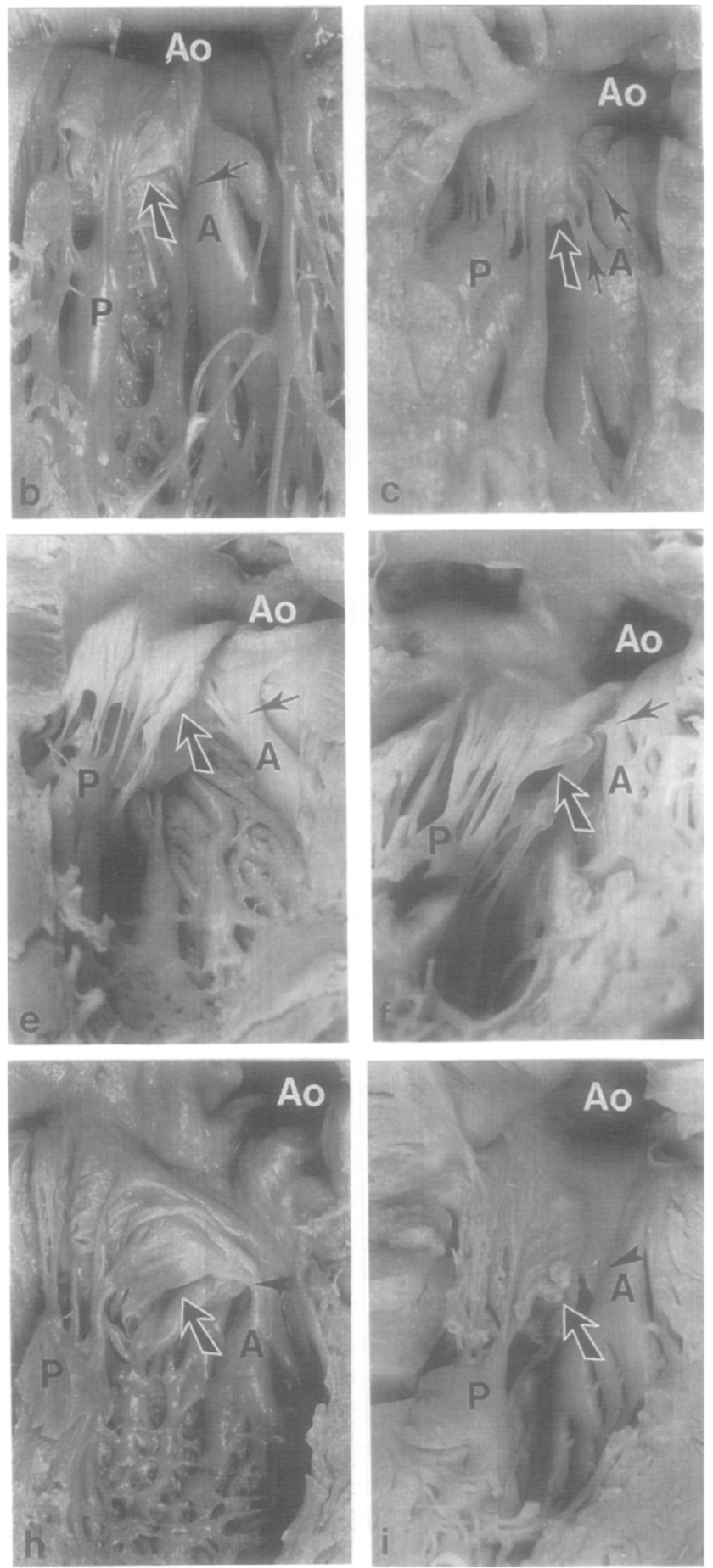

Fig. 3. The spectrum of parachute-like asymmetric mitral valves. a through c, Grade I asymmetric mitral valves demonstrating elongated anterolateral papillary muscles (cases 2 and 4). d through f, Asymmetric grade II mitral valves with only a few chords attached to the elongated anterolateral papillary muscle (cases 11 and 16). $\mathbf{g}$ through $\mathbf{i}$, Asymmetric grade III mitral valves with the valve leaflet directly attached to the anterolateral papillary muscle (cases 24 and 25 ). The mitral valve orifices are indicated by dots in the drawings and by thick arrows on the photomicrographs. Thin arrows indicate chordal attachments and arrowheads indicate direct attachment of the valve leaflet to the anterolateral papillary muscle. $A$, Anterolateral papillary muscle; $A o$, aorta; $P$, posteromedial papillary muscle. 
Table II. Left ventricular size and mitral valve annular size in normal hearts and hearts with parachute-like asymmetric mitral valve with abnormal anterolateral papillary muscle

\begin{tabular}{|c|c|c|c|c|}
\hline Group & No. & $\begin{array}{l}\text { LV length } \\
(\mathrm{mm})\end{array}$ & $M V / L V$ & $M V / T V$ \\
\hline Nor & 19 & $36(16)$ & $0.29(0.06)$ & $0.86(0.06)$ \\
\hline Asymmetric & 26 & $37(11)$ & $0.24(0.05)$ & $0.70(0.24)$ \\
\hline$p$ Value & & 0.75 & $<0.01$ & 0.01 \\
\hline
\end{tabular}

Standard deviations given in parentheses. $L V$, Left ventricle; $M V$, mitra valve; $T V$, tricuspid valve.

divided all parameters measured in the anterolateral papillary muscle complex by those measured in the posteromedial papillary muscle complex to quantify mitral valve asymmetry (Table III). In the normal valves these ratios were about 1 , indicating symmetry. In the asymmetric mitral valves this ratio for the length of the papillary muscles and the distances from the apex to the base and to the tip of the papillary muscles was significantly larger, indicating that the anterolateral papillary muscles were longer and displaced toward the mitral valve anulus. The chords and leaflets were shorter at the side of the anterolateral papillary muscle.

Neither the size nor the location of the posteromedial papillary muscle in the hearts with an asymmetric mitral valve differed significantly from respective findings in normal hearts (Table IV). Significant differences, however, were found for the anterolateral papillary muscle, which was longer and displaced toward the base of the heart compared with findings in normal hearts. Despite the longer anterolateral papillary muscle, the chords were attached more basally to the papillary muscle in asymmetric mitral valves.

\section{Discussion}

In this paper we describe two types of mitral valve malformations that are both characterized by focalized attachment of chords to one papillary muscle. The essential difference is the number of papillary muscles: one or two. The morphologic features of mitral valves with two papillary muscles, however, do not fit with the original description of parachute valves. ${ }^{1}$ We use the term parachute-like asymmetric mitral valve to discriminate this malformation from the "true parachute valves" with one papillary muscle.

Parachute-like asymmetric mitral valve. The main characteristics of asymmetric mitral valves are unequal distribution of chords and one normal and



a



Fig. 4. A schematic drawing (a) and a photograph (b) of the single parachute mitral valve with one papillary muscle to which all chords are attached. The mitral valve orifice is indicated by dots (a) and by a thick arrow (b). Ao, Aorta.

one elongated papillary muscle that is displaced toward the mitral valve anulus.

We have observed a spectrum of asymmetry in which especially grade III hearts have a parachutelike appearance because the abnormal papillary muscle receives no chords. In these hearts the abnormal papillary muscle is attached to the ventricular wall in such a way that it might be interpreted as a trabecula ${ }^{6}$ or might not be recognized at all. ${ }^{1}$ However, its location and the attachment of the valve leaflets make this myocardial structure a papillary muscle. The spectrum of asymmetry we found supports this. The commissure can still be defined as the junction between two leaflets, and the oblique and eccentric orifice is located between the two papillary muscles ${ }^{7}$ but is not a valvular "cleft" inasmuch as its closure will not restore normality, ${ }^{8}$ nor will it be opened by pulling of the tensor apparatus. ${ }^{9}$ In most hearts the anterolateral papillary muscle was abnormal. This has also been found by others. ${ }^{4,10}$

Long papillary muscles, attached at their lateral side to the ventricular wall, have been described in normal adult human hearts ${ }^{11}$ and in adult rodent hearts ${ }^{12}$ and are normally present in early fetal hearts as well. ${ }^{13}$ Papillary muscle development normally results in symmetry, ${ }^{14-16}$ and the presently described asymmetry seems to be the result of abnormal development of one papillary muscle and tensor apparatus.

Clinical implications. Stenosis is typical for the parachute valve ${ }^{17,18}$ and in our study all the abnor- 
Table III. Ratios of measurements made at anterolateral commissure and posteromedial commissure of normal mitral valves and parachute-like mitral valves with abnormal anterolateral papillary muscle

\begin{tabular}{ccccccc}
\hline Group & $\begin{array}{c}\text { Base of PM } \\
\text { to apex }\end{array}$ & $\begin{array}{c}\text { Tip of PM } \\
\text { to apex }\end{array}$ & $\begin{array}{c}\text { Length of } \\
\text { ALPMt/PMPM }\end{array}$ & $\begin{array}{c}\text { Length of } \\
\text { ALPMc/PMPM }\end{array}$ & $\begin{array}{c}\text { Length of } \\
\text { leaflets }\end{array}$ & $\begin{array}{c}\text { Length of } \\
\text { chords }\end{array}$ \\
\hline Normal & $0.93(0.14)$ & $1.03(0.07)$ & $1.11(0.16)$ & $1.11(0.16)$ & $0.98(0.13)$ & $1.04(0.25)$ \\
Asymmetric & $1.58(0.52)$ & $1.55(0.37)$ & $1.59(0.72)$ & $0.98(0.37)$ & $0.74(0.33)$ & $0.81(0.26)$ \\
$p$ Value & $<0.01$ & $<0.01$ & 0.01 & 0.16 & 0.01 & 0.01 \\
\hline
\end{tabular}

Standard deviations given in parentheses. $A L P M$, Anterolateral papillary muscle; $A L P M c$, ALPM from base to chords; $A L P M t$, ALPM from base to tip; $P M$, papillary muscles; $P M P M$, posteromedial papillary muscle.

Table IV. Length and location of ALPM and PMPM in normal mitral valves and parachute-like asymmetric mitral valves with abnormal anterolateral papillary muscle

\begin{tabular}{cccccccc}
\hline Group & $\begin{array}{c}\text { Base PMPM } \\
\text { to apex }\end{array}$ & $\begin{array}{c}\text { Tip PMPM } \\
\text { to apex }\end{array}$ & $\begin{array}{c}\text { Length of } \\
\text { PMPM }\end{array}$ & $\begin{array}{c}\text { Base ALPM } \\
\text { to apex }\end{array}$ & $\begin{array}{c}\text { Tip ALPM } \\
\text { to apex }\end{array}$ & $\begin{array}{c}\text { Length of } \\
\text { ALPMt }\end{array}$ & $\begin{array}{c}\text { Length of } \\
\text { ALPMc }\end{array}$ \\
\hline Normal & $0.26(0.07)$ & $0.61(0.09)$ & $0.34(0.06)$ & $0.24(0.06)$ & $0.62(0.08)$ & $0.37(0.05)$ & $0.37(0.05)$ \\
Asymmetric & $0.29(0.11)$ & $0.60(0.14)$ & $0.31(0.06)$ & $0.42(0.15)$ & $0.86(0.13)$ & $0.46(0.16)$ & $0.30(0.10)$ \\
$\quad p$ Value & 0.36 & 0.80 & 0.09 & $<0.01$ & $<0.01$ & 0.02 & 0.01 \\
\hline
\end{tabular}

All values are divided by the left ventricular length. Standard deviations given in parentheses. $A L P M$, Anterolateral papillary muscle; $A L P M c$, ALPM from base to chords; $A L P M t$, ALPM from base to tip; PMPM, posteromedial papillary muscle.

mal mitral valves, even those with mild asymmetry (grade I), were also stenotic compared with the values reported by Rosenquist. ${ }^{2}$ Stenosis at the orifice level was only present in grade II and III hearts but an oblique, eccentric orifice did not result in a smaller orifice per se.

The presence and location of papillary muscles can be visualized by two-dimensional echocardiography, ${ }^{19,20}$ especially when the blood flow is also studied by Doppler interrogation. ${ }^{21}$ Anomalous insertion of the papillary muscles into the valve leaflets, a morphologic condition that is comparable with the malformed papillary muscle in asymmetric mitral valves, can only be identified by nonstandard cross-sectional planes. ${ }^{22}$

In addition to mitral stenosis, other malformations were present in our cases. An abnormal aortic arch often coexists with parachute mitral valves, ${ }^{1,2,19,23}$ and this was present in many of our specimens; however, Shone's complex ${ }^{1}$ was not found. When other malformations are present, restoration of the mitral valve seems to be of a lower priority and is not even done for parachute mitral valves ${ }^{3}$; additionally, this type of stenosis is not easy to repair. True parachute mitral valves are not candidates for balloon angioplasty and only relatively poor results were achieved in children who had disproportionate chordal attachments to one of the papillary muscles. ${ }^{24}$ Subdividing the papillary muscle into anterior and posterior portions to widen the orifice has proved to be successful in some parachute valves. ${ }^{18,25}$ Whether this technique can also be used for asymmetric mitral valves seems to be questionable.

We gratefully thank E. A. van der Velde, MSc, for his help with the statistical analysis and J. H. Lens for the photographic work.

\section{REFERENCES}

1. Shone JD, Sellers RD, Anderson RC, Adams P, Lillehei CW, Edwards JE. The developmental complex of "parachute mitral valve," supravalvular ring of left atrium, subaortic stenosis, and coarctation of aorta. Am J Cardiol 1963;11:71425.

2. Rosenquist GC. Congenital mitral valve disease associated with coarctation of the aorta: a spectrum that includes parachute deformity of the mitral valve. Circulation $1974 ; 49$ : 985-93.

3. Bolling SF, Iannettoni MD, Dick M, Rosenthal A, Bove EL. Shone's anomaly: operative results and late outcome. Ann Thorac Surg 1990;49:887-93.

4. Anderson RH, Macartney FJ, Shinebourne EA, Tynan M. Mitral valve anomalies and supravalvular ring. In: Anderson RH, Macartney FJ, Shinebourne EA, Tynan M, eds. Pediatric cardiology. Vol. 2. New York: Churchill Livingstone, 1987:1025-56.

5. Draulans-Noë HAY, Wenink ACG, Quaegebeur J. Single papillary muscle ("parachute valve") and double-orifice left ventricle in atrioventricular septal defect convergence of chordal attachment: surgical anatomy and results of surgery. Pediatr Cardiol 1990;11:29-35.

6. Bett JHN, Stovin PGI. Parachute deformity of the mitral valve. Thorax 1969;24:632-6.

7. Victor S, Nayak VM. Definition and function of commissures, slits and scallops of the mitral valve: analysis in 100 hearts. Asia Pac Thorac Cardiovasc Surg 1994;3:10-6.

8. Anderson RH, Zuberbuhler JR, Penkoske PA, Neches WH. 
Of clefts, commissures, and things. J Thorac Cardiovasc Surg 1985;90:605-10.

9. Van Praagh R, Papagiannis J, Bar-El YT, Schwint OA. The heart in Down syndrome: pathologic anatomy. In: Marino B, Pueschel SM, eds. Heart disease in persons with Down syndrome. Baltimore: Paul H. Brookes, 1996:69-110.

10. Banerjee A, Thomas K, Silverman NH. Echocardiographic evaluation of congenital mitral valve anomalies in children. Am J Cardiol 1995;76:1284-91.

11. Ranganathan $\mathrm{N}$, Silver $\mathrm{MD}$. The mitral valve in man: a review of anatomy and its clinical significance. Anat Clin 1981;2:361-7.

12. Icardo JM, Arrechedera H, Colvee E. The atrioventricular valves of the mouse. I. A scanning electron microscopy study. J Anat 1993;182:87-94.

13. Oosthoek PW, Wenink ACG, Wisse LJ, Gittenberger-de Groot AC. Development of the papillary muscles of the human mitral valve: implications for malformations. [abstract]. Cardiol Young 1996;6:S38.

14. Lam JHC, Ranganathan N, Wigle ED, Silver MD. Morphology of the human mitral valve. I. Chordae tendineae: a new classification. Circulation 1970;41:449-58.

15. Ranganathan N, Lam JHC, Wigle ED, Silver MD. Morphology of the human mitral valve. II. The valve leaflets. Circulation 1970;41:459-67.

16. Carpentier A, Branchini B, Cour JC, et al. Congenital malformations of the mitral valve in children. $\mathbf{J}$ Thorac Cardiovasc Surg 1976;72:854-66.

17. Ruckman RN, van Praagh R. Anatomic types of congenital mitral stenosis: report of 49 autopsy cases with consideration of diagnosis and surgical implications. Pediatr Cardiol 1978; 42:592-601.
18. Barbero-Marcial M, Riso A, De Albuquerque AT, Atik E, Jatene A. Left ventricular apical approach for the surgical treatment of congenital mitral stenosis. J Thorac Cardiovasc Surg 1993;106:105-10.

19. Celano V, Pieroni DR, Morera JA, Roland J-MA, Gingell RL. Two-dimensional echocardiographic examination of mitral valve abnormalities associated with coarctation of the aorta. Circulation 1984;69:924-32.

20. Snider AR, Roge CL, Schiller NB, Silverman NH. Congenital left ventricular inflow obstruction evaluated by two-dimensional echocardiography. Circulation 1980;61: 848-55.

21. Grenadier E, Sahn DJ, Valdes-Cruz LM, Allan HD, Oliveira Lima C, Goldberg SJ. Two-dimensional echo Doppler study of congenital disorders of the mitral valve. Am Heart $\mathrm{J}$ 1984;107:319-25.

22. Klues HG, Roberts WC, Maron BJ. Anomalous insertion of papillary muscle directly into anterior mitral leaflet in hypertrophic cardiomyopathy: significance in producing left ventricular outflow obstruction. Circulation 1991;84: 1188-97.

23. Becker AE, Becker MJ, Edwards JE. Anomalies associated with coarctation of aorta: particular reference to infancy. Circulation 1970;41:1067-75.

24. Spevak PJ, Bass JL, Ben-Sachar G, et al. Balloon angioplasty for congenital mitral stenosis. Am J Cardiol 1990; 66:472-6.

25. Carpentier A, Guerinon J, Deloche A, Fabiani JN, Relland J. Pathology of the mitral valve: introduction to plastic and reconstructive valve surgery. In: Kalmanson D, ed. The mitral valve: a pluridisciplinary approach. London: Edward Arnold, 1976:65-77.

\section{Availability of Journal back issues}

As a service to our subscribers, copies of back issues of The Journal of Thoracic and Cardiovascular Surgery for the preceding 5 years are maintained and are available for purchase from Mosby at a cost of $\$ 15.00$ per issue until inventory is depleted. The following quantity discounts are available: $25 \%$ off on quantities of 12 to 23 , and one third off on quantities of 24 or more. Please write to Mosby-Year Book, Inc., Subscription Services, 11830 Westline Industrial Drive, St. Louis MO 63146-3318, or call 800-453-4351 or 314-453-4351 for information on availability of particular issues. If unavailable from the publisher, photocopies of complete issues may be purchased from UMI, 300 N. Zeeb Rd., Ann Arbor, MI 48106, 313-761-4700. 